\title{
Air Flow Control of Centrifugal Fans for Personal Protection EQuipMent
}

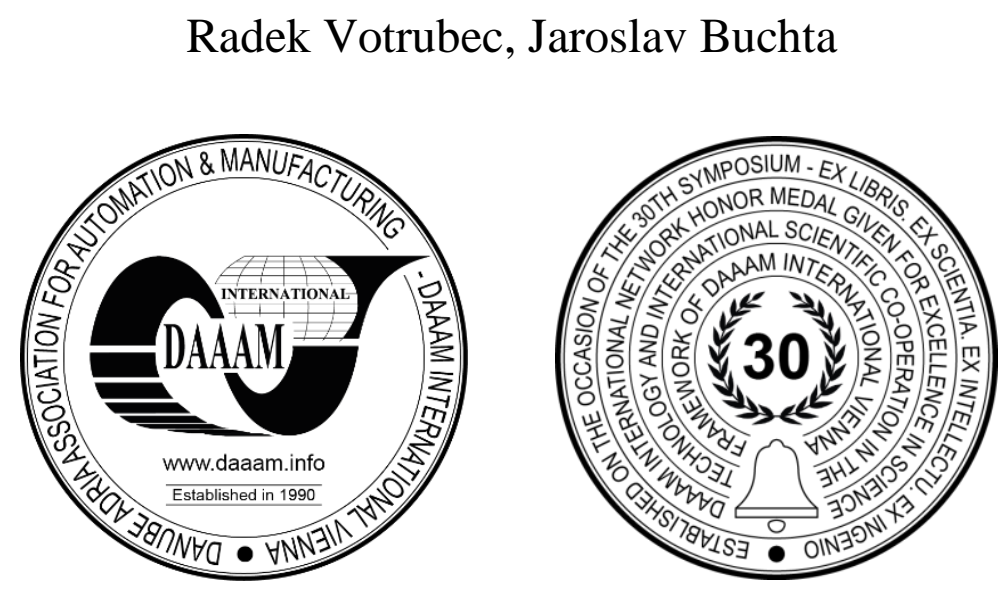

This Publication has to be referred as: Votrubec, R[adek] \& Buchta, J[aroslav] (2019). Air Flow Control of Centrifugal Fans for Personal Protection Equipment, Proceedings of the 30th DAAAM International Symposium, pp.0268-0275, B. Katalinic (Ed.), Published by DAAAM International, ISBN 978-3-902734-22-8, ISSN 1726-9679, Vienna, Austria DOI: $10.2507 / 30$ th.daaam.proceedings.035

\begin{abstract}
The aim of the development is experimental investigation of centrifugal fans for a personal protection equipment. The fan has to drive the contaminated air through the filters and then into the mask of workers. The fan is tested on the test stand, the characteristics and performances are evaluated. The dependency of flow rate on the voltage and electric current is the most important for us. We want to control the flow without a flow sensor that is too expensive and takes up space in the mask.
\end{abstract}

Keywords: BLDC motor; flow control; centrifugal fan; microprocessor; protective mask.

\section{Introduction}

A brushless DC motor (BLDC) is an electrical synchronous motor that has a rotor with permanent magnets and a stator with wound coils. This design can eliminate the biggest shortcoming of common brushed DC electrical motors, in which powered coils are located on a rotating rotor. Windings are connected to the commutator segments that work as mechanical inverters. The carbon brushes transfer electrical energy from a power supply to commutation segments inside a motor in the brushed DC motors. In BLDC motors, a semiconductor converter replaces the mechanical commutation. For rotation of the rotor, knowing of its relative position to a stator is necessary. It can be obtained by the using of a position sensor or by the indirect measurement of electrical units. According to the position of the rotor, microcontroller switches the coils in the stator.

The BLDC motors can be divided into two main groups with respect to a used control method:

- Motors with embedded position sensor;

- Motors without position sensor.

The widely used sensors for measurement of the actual position of the rotor are Hall effect sensors. This type of motors cannot be used in a High Flow Filter Unit application. The reason for this limitation is rising costs for mass production of devices. Therefore, we chose the second type of BLDC motors that does not have position sensor. 
The designed control system gets the position of the rotor by the analyzing of electromotive force feedback. During their movement, permanent magnets on the rotor generate low voltage in the coils of a stator. Voltage value depends on the rotor's position. The control circuit detects zero position using the measurement of voltage and current in each coil of the motor. The issue that we found in this type of control systems appeared during the motor starting, when feedback electromotive force is undetectable due to its small value. Therefore, we had to estimate the position of the rotor during motor starting for the overcoming of this issue.

The block scheme of control circuit is in figure 1. The internal control loop, based on current and voltage measurements in all phases, provides BLDC motor control. An external control loop allows motor speed control. The speed reference can be entered either via a potentiometer connected to the microprocessor input or via a serial line.

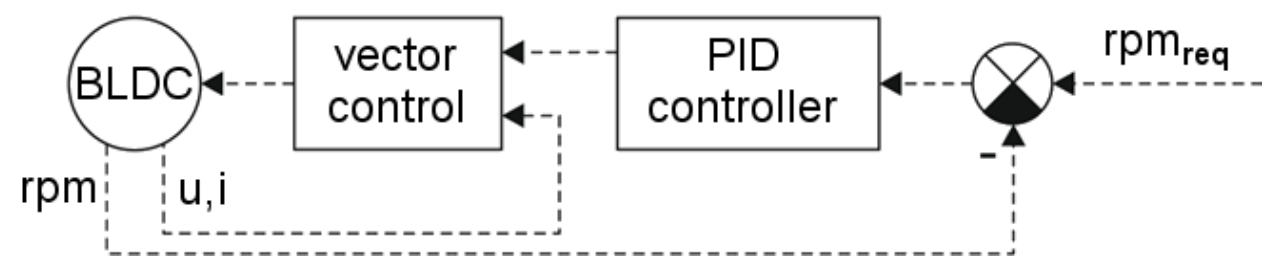

Fig. 1. The block scheme of control circuit

Centrifugal fans are used in a plenty of applications. Flow in centrifugal fan is very complex and many researchers investigated it numerically and experimentally [1], [2] or [3]. Our work belongs to experimental research. There are a lot of papers about motor control and its application [4], [5] and [6].

\section{Experimental setup}

The first version of a PCB was designed according to the first available BLDC motor integrated to the fan that is showed on the figure 2. This motor has eight poles on its magnet and six stator coils. Four serially connected Li-ion batteries power the High Flow Filter Unit system with working voltage from $17 \mathrm{~V}$ in a fully charged mode to $12 \mathrm{~V}$ in a discharged mode. The maximum rpm that the motor is able to deliver is 10000 . The final version of the device had to get maximal speed up to $18000 \mathrm{rpm}$.

Due to the type of a chosen motor (without a position sensor), we had to design an algorithm that uses vector method for motor control.

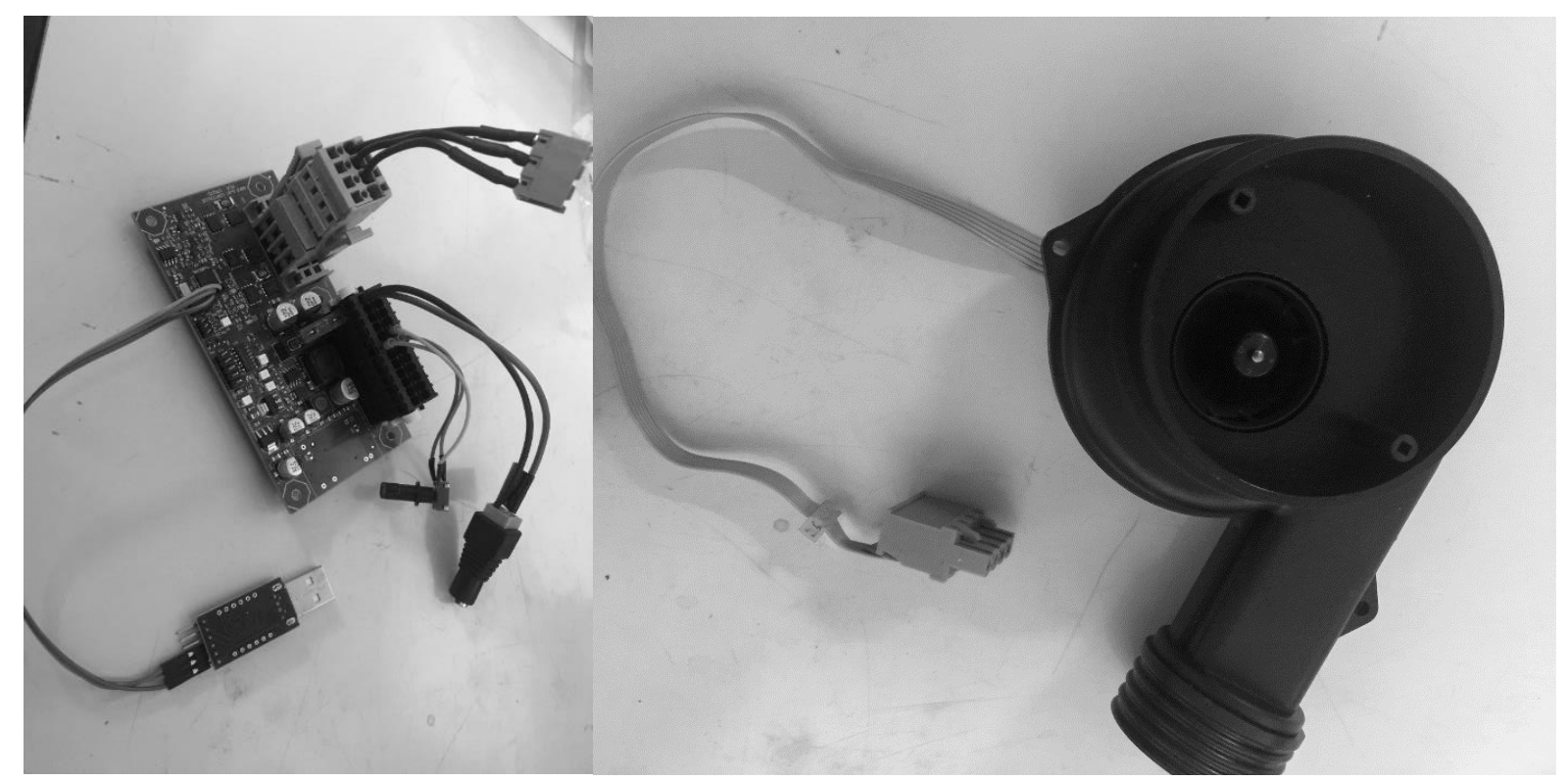

Fig. 2. The first version of PCB and BLDC motor for the fan of High Flow Filter Unit

Electrical circuit diagram of the first version of PCB is showed on the figure 3. It consists of five parts: microprocessor (Sheet MCU), motor driver (Sheet PhaseSwitch), power supply (Sheet Power), external signals (Sheet ExtSignals) and connectors (Sheet Connectors). 


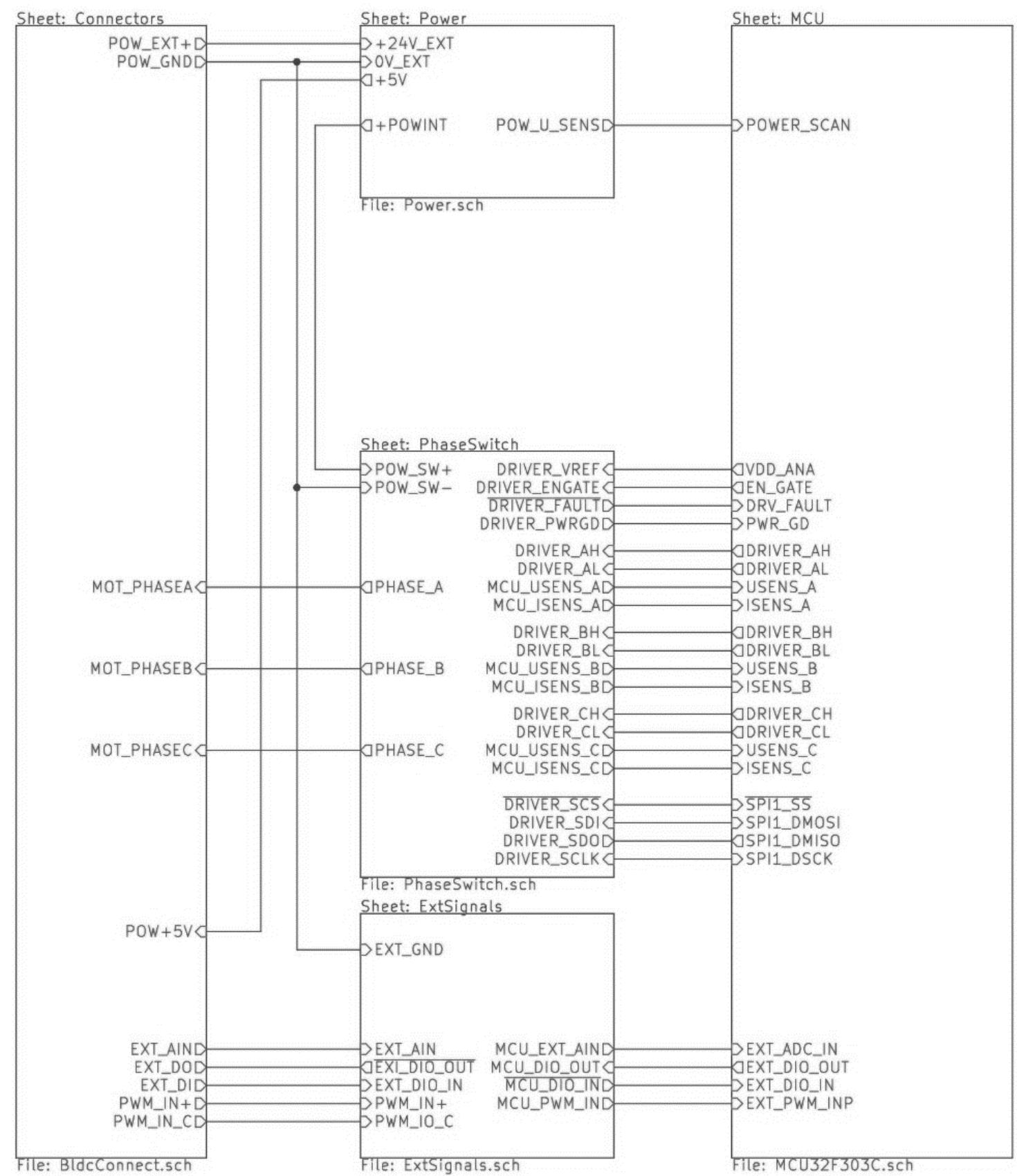

Fig. 3. The first version of a PCB

During the development of the control system for a High Flow Filter Unit, research was split into two parts. The first part improves a vector control algorithm and the second part designs a PCB for scalar control. The newly designed control board uses serial bus for communication and allows connection of peripheral devices such as bottoms, displays, pressure and flow sensors. During the design of a new PCB design that supports embedded implementation was also took in account. Consequently, it was necessary to make a board as small as possible. The software for implementation of the motor control algorithm and the values of tuning parameters required for measurement were also designed during this research.

The main task for the second generation of a DPS that is still based on a vector control algorithm was to optimize a few small drawbacks of the first version. The second version of the PCB uses more appropriate transistors PMDPB30XN instead of overlarge BSC014N06NS. New transistors still have enough power and are combined into pairs in a single case. In addition, inputs for connection of three user bottoms and LCD display were added for the ensuring of effective communication between a user and the control system. A DSP also includes a 3-channel analog-to-digital converter from 0 to $5 \mathrm{~V}$. It makes the connection of analog pressure and flow sensors possible. Also, the second generation of a PCB supports USB communication. Photo of the second generation of a PCB is presented on the figure 4. 


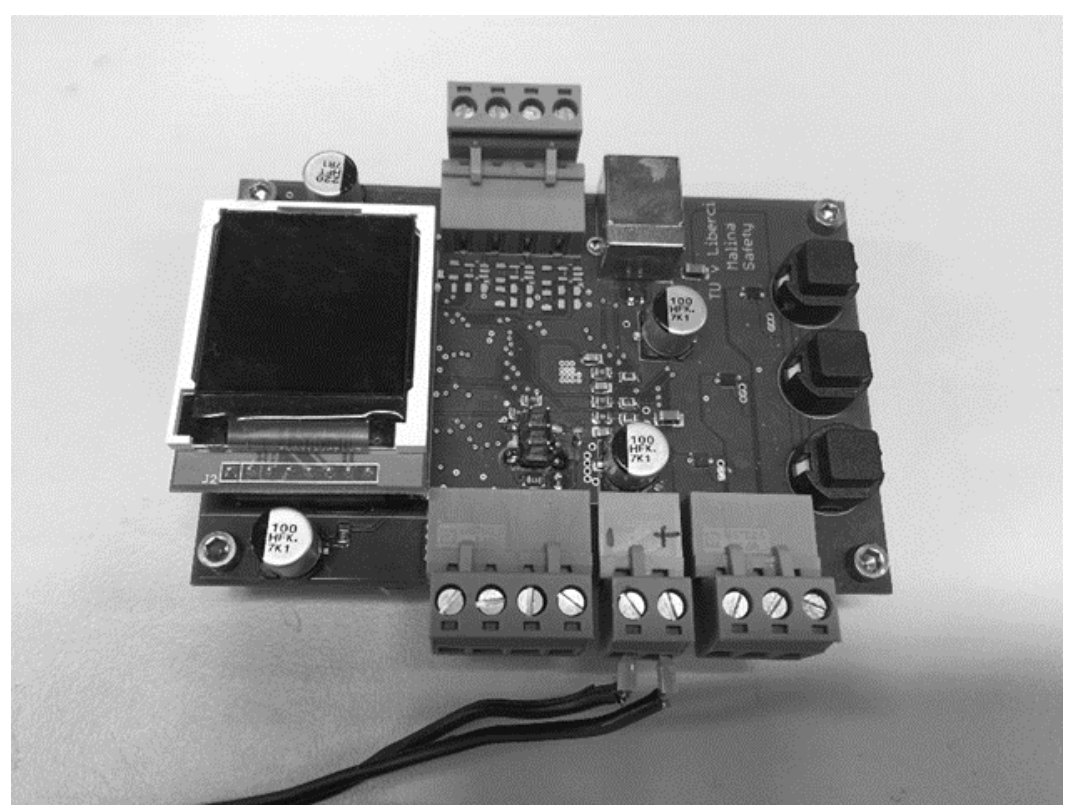

Fig. 4. A photo of the second generation DSP.

The third generation of the control board with scalar control algorithm was designed at the same time as the second generation. Its photo is shown on the figure 5. This version is the smallest one and the most cost-effective. For this PCB, a new algorithm based on scalar control was designed. This control method is the most reliable for BLDC motors, especially during the motor starting. The efficiency of scalar control is comparable to the efficiency of the vector control method.

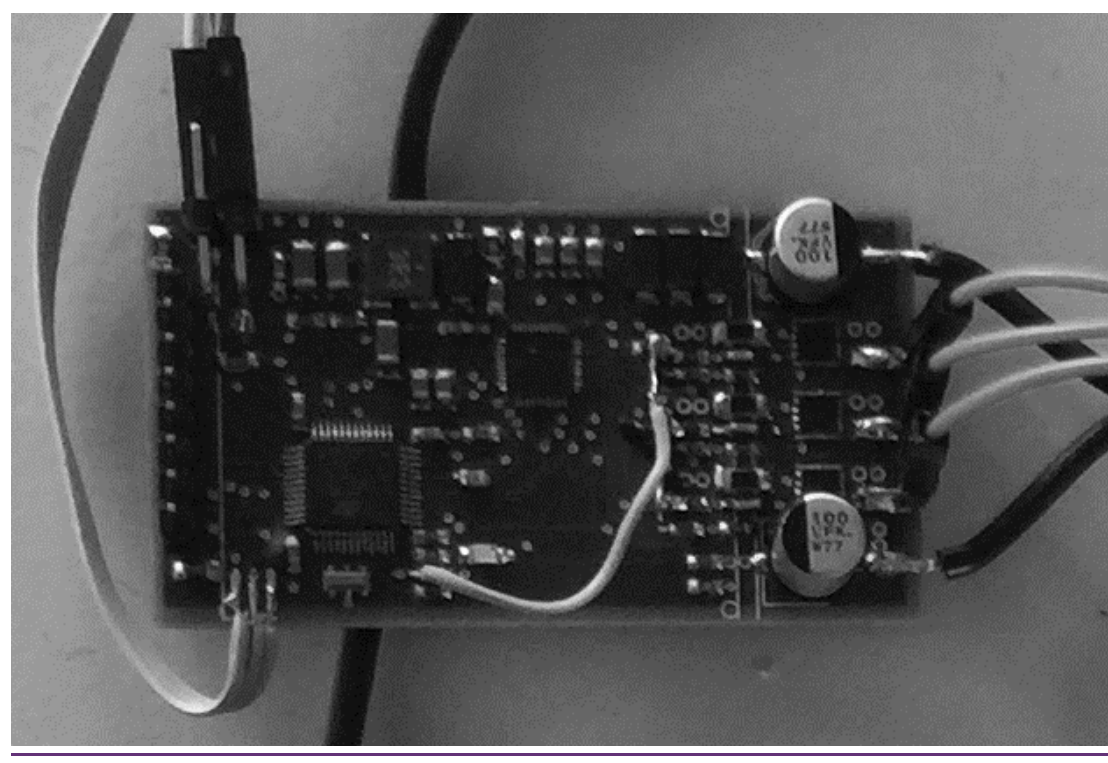

Fig. 5. The photo of the third generation PCB

Our device was used to research the influence of using 3D printing technologies in the manufacture of fan blades [7]. The most important thing is to adjust optimal parameters of PID controller [8].

\section{Measurement and control of the fan}

Several variables can be measured in real time on the bldc motor. Current and voltage are important for power calculation. Speed is measured for subsequent flow estimation. All variables are monitored at increasing pwm ratio for several replaceable filters with different load. Electric current and rotation speed are in figure 6 and figure 7. 


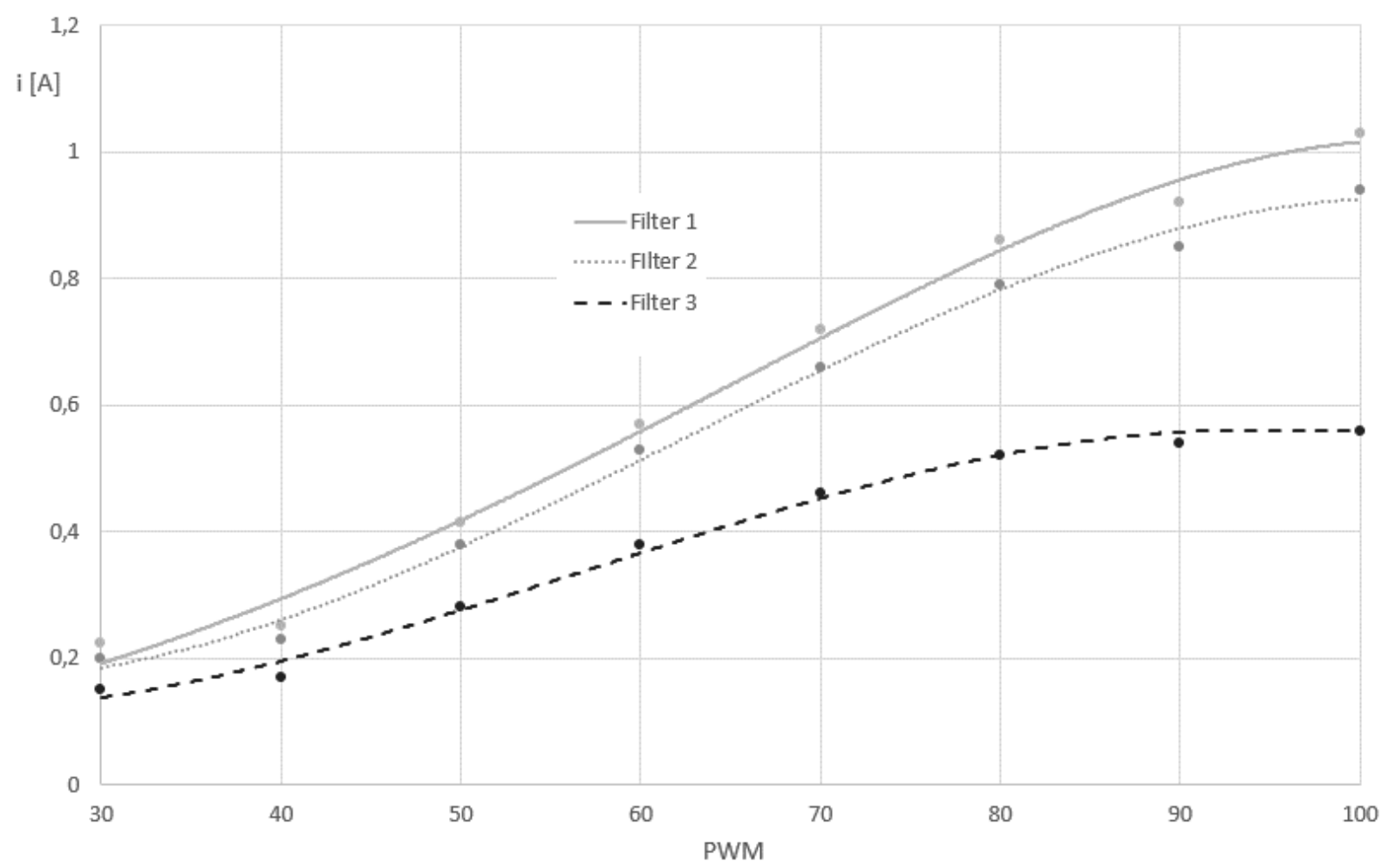

Fig. 6. Current values at increasing pwm ratio

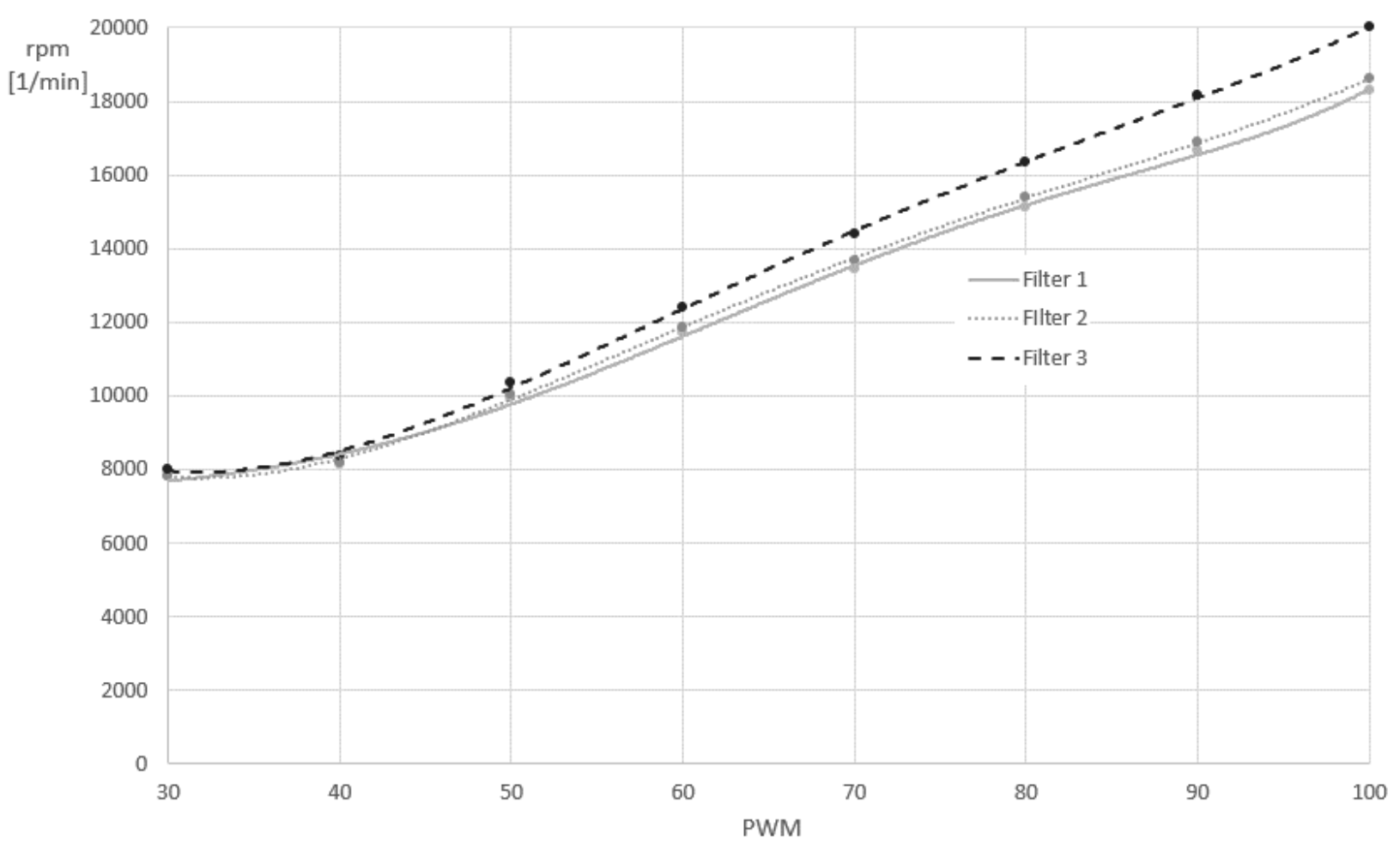

Fig. 7. Rotation speed values at increasing pwm ratio 


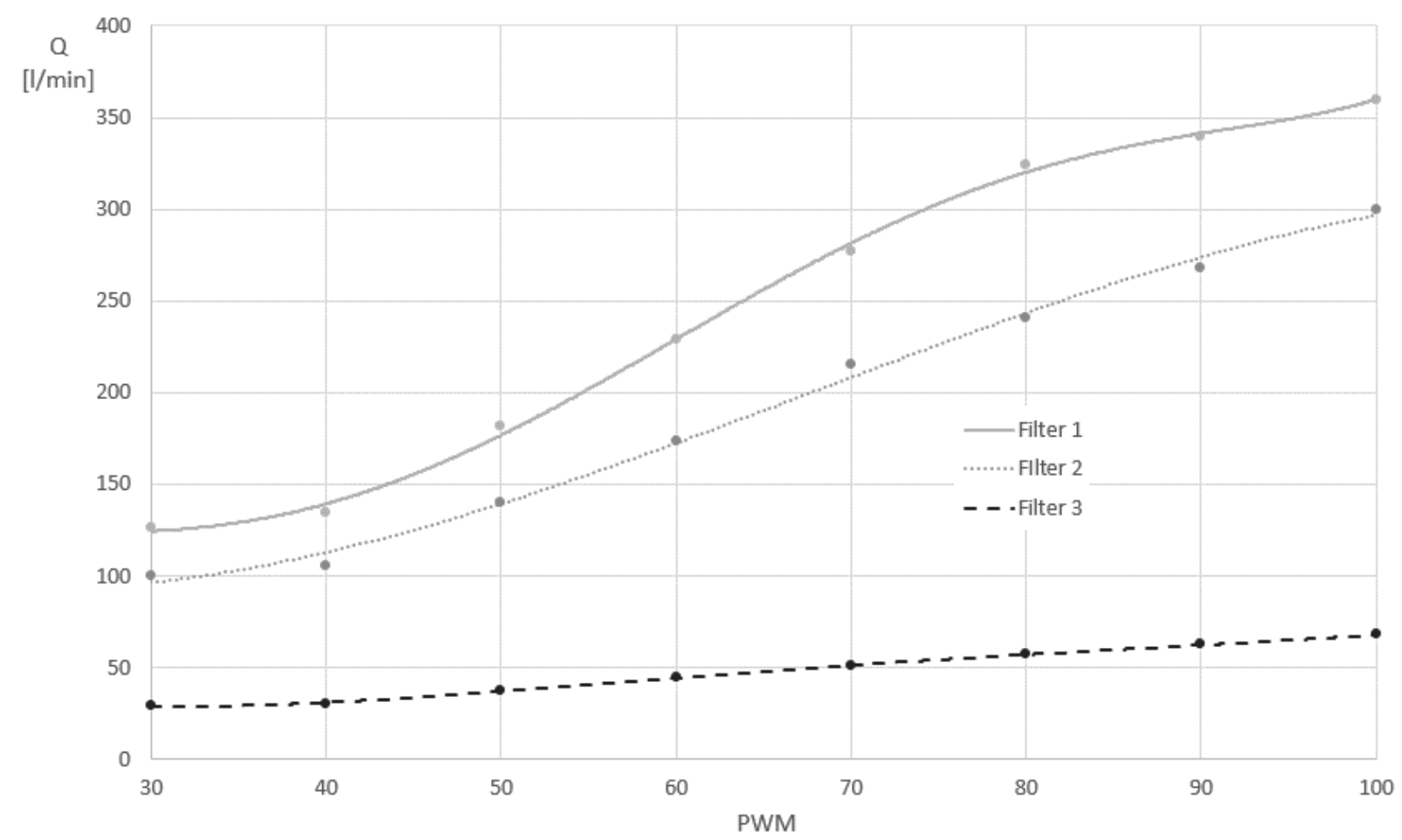

Fig. 8. Flow rate values at increasing pwm ratio

The flow values in figure 8 were measured with the flow meter in figure 9. It is possible to add various filter to the fan. The power values in figure 10 were calculated from voltage and current. The flow rate dependence on rotation speed and power was constructed as a two-dimensional function, figure 11.

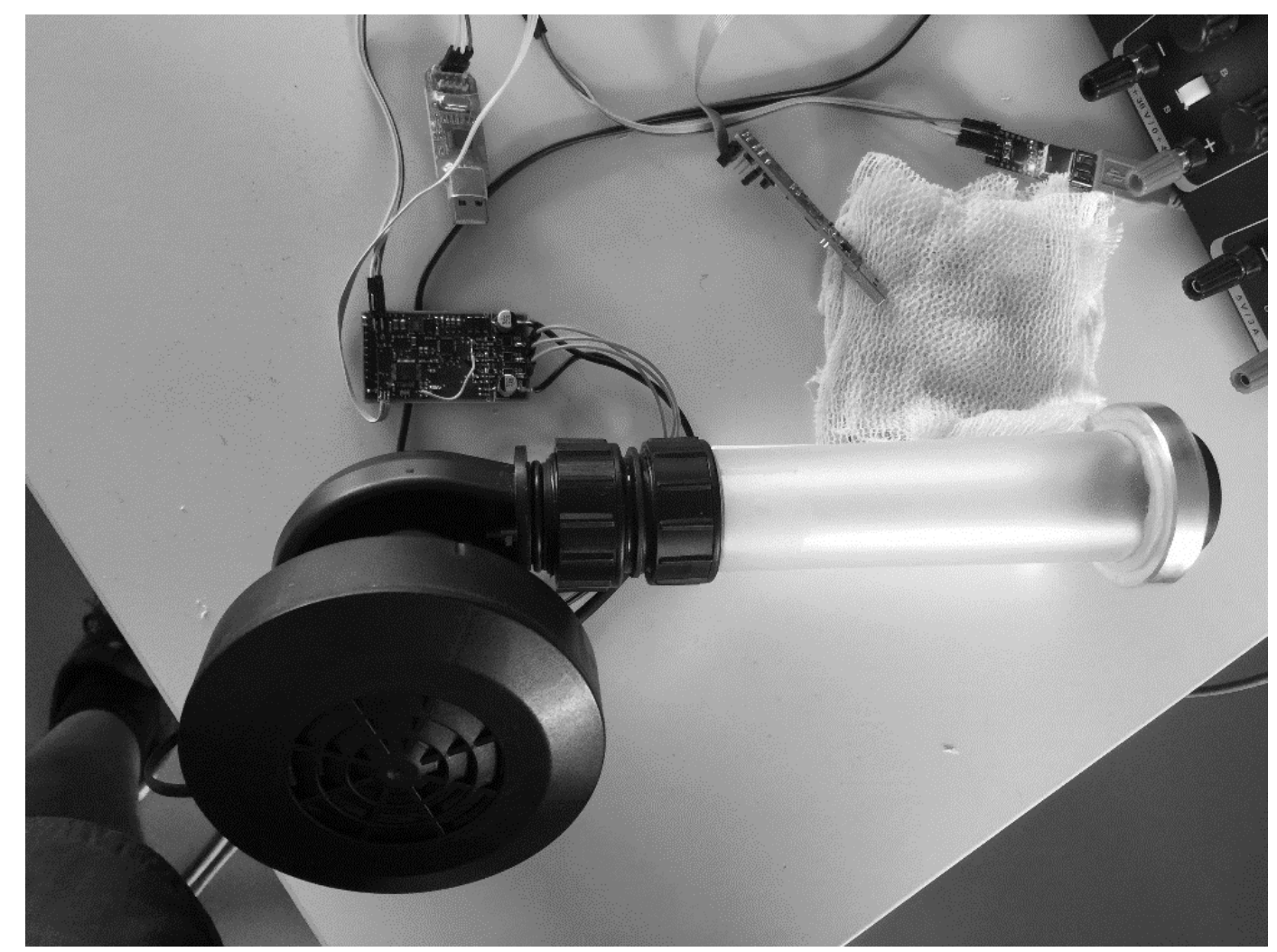

Fig. 9. The fan with flow rate sensor 


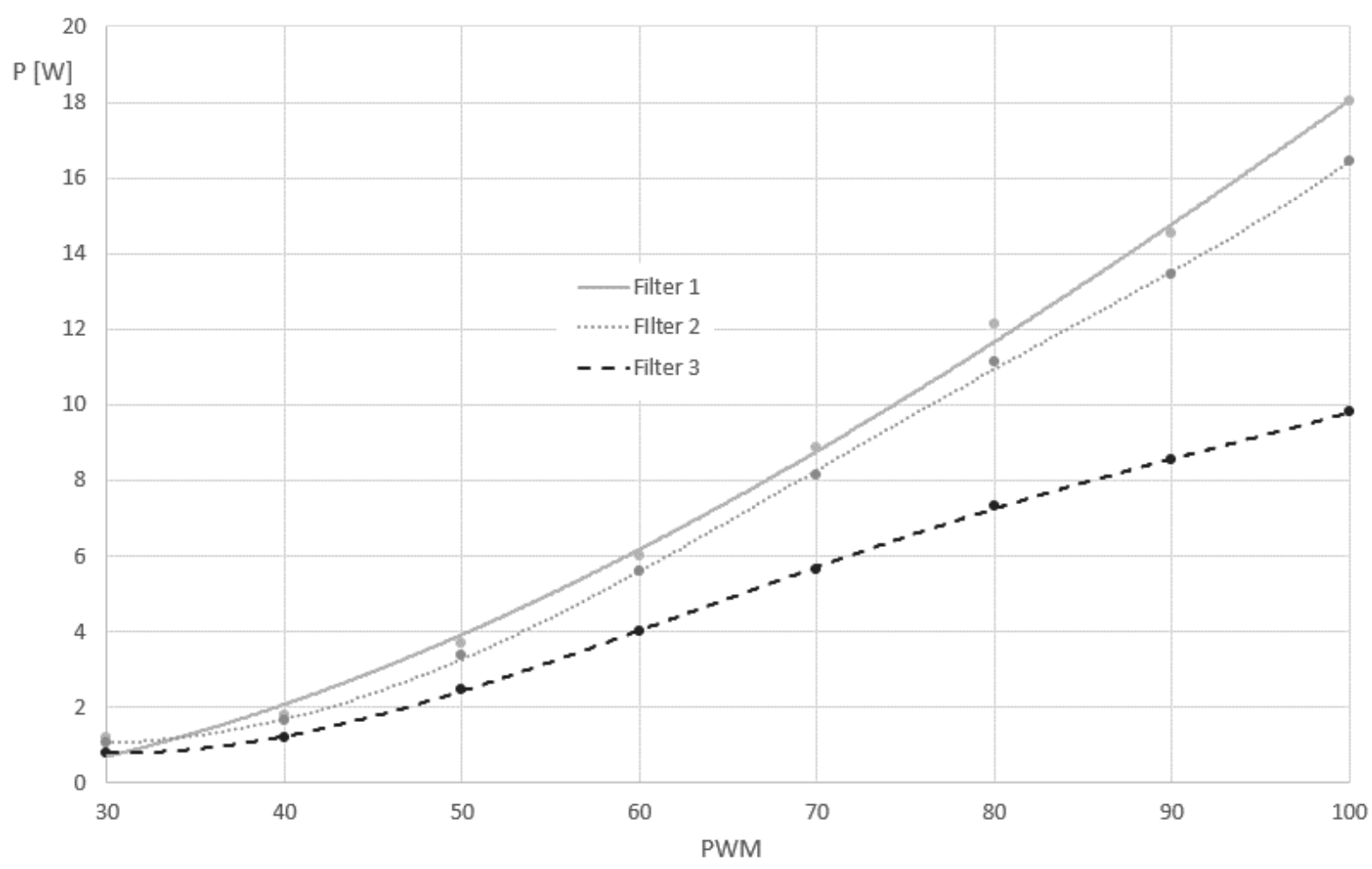

Fig. 10. Power values at increasing pwm ratio

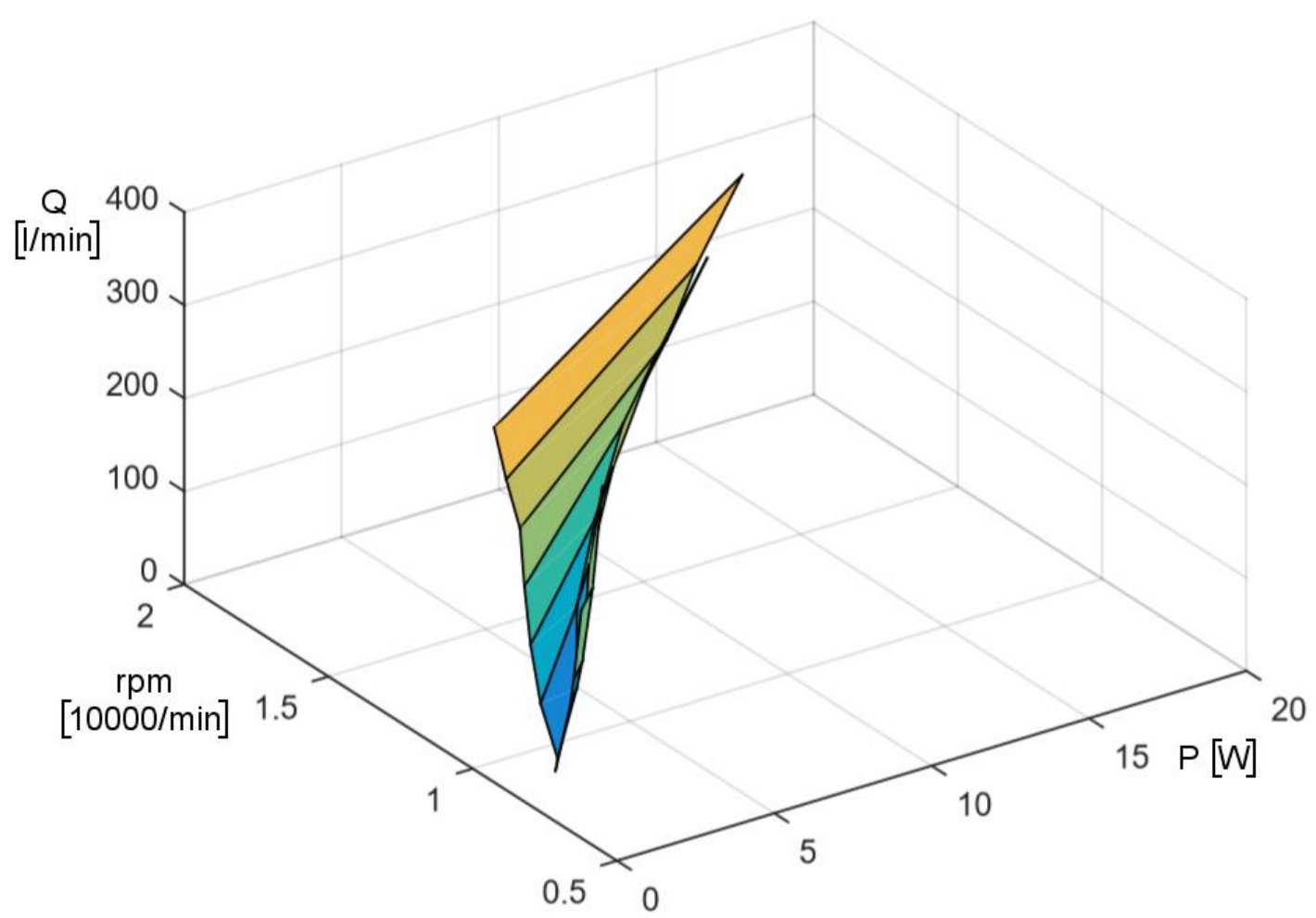

Fig. 11. Flow rate on power and rotation speed dependency

This measured dependence is used to estimate the flow based on the measured values of current, voltage and speed. The scheme of created control circuit is in figure 12 . 


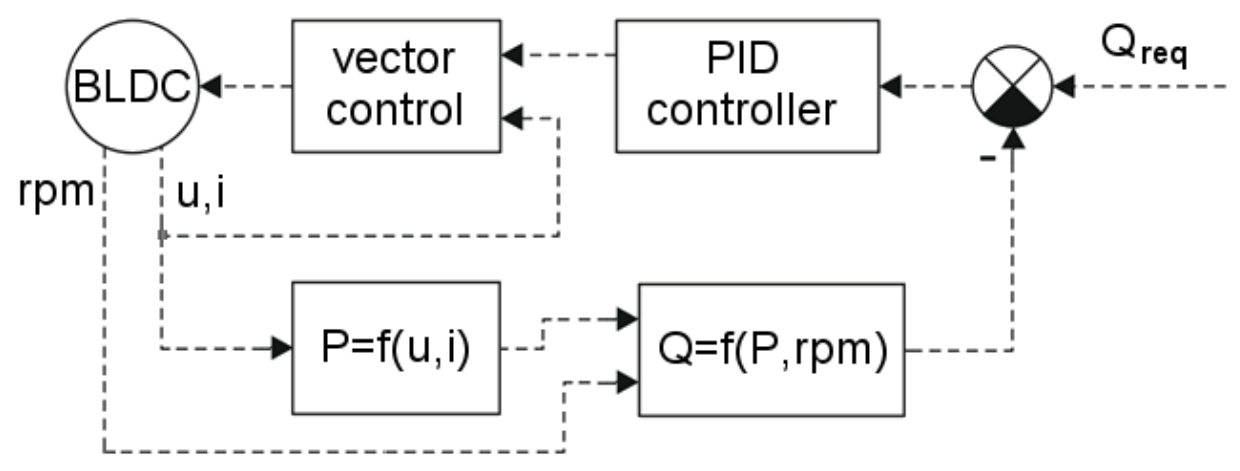

Fig. 12. Control of flow rate

\section{Conclusion}

Two methods of BLDC control were realized, scalar and vector control. Both engine control methods had comparable efficiency. The scalar method has a more reliable start-up, is significantly cheaper and less CPU consuming. Its computing capacity can then be better utilized for the user interface of the High Flow Filter Unit, display control, etc. The dependency of flow rate on the rotation speed, voltage and electric current was described. We used it to control the air flow without a flow sensor that is too expensive and takes up space in the High Flow Filter Unit.

\section{Acknowledgments}

This paper was created in the framework of project "Applied research in the field of the new generation of personal protective equipment for the demands of joint rescue service" no. VI20172020052, supported by Ministry of Interior of the Czech Republic.

\section{References}

[1] Gessner, F.B. (1967) An experimental study of centrifugal fan inlet flow and its influence on fan performance, ASME paper no 67. 1967. American Society of Mechanical Engineers.

[2] Zhang, J.; Chu, W.; Zhang, H.; Wu, Y. a X. Dong. (2016) Numerical and experimental investigations of the unsteady aerodynamics and aero-acoustics characteristics of a backward curved blade centrifugal fan. Applied Acoustics [online]. 2016, 110, 256-267 [cit. 2019-10-13]. DOI: 10.1016/j.apacoust.2016.03.012. ISSN 0003682X.

[3] Catana, R.M.; Cican, G. (2015) Detailed gas dynamic study of performances for two types turbofan configurations, 26th DAAAM International Symposium on Intelligent Manufacturing and Automation, DAAAM 2015, ISSN 17269679, Vienna, Austria

[4] Livinti, P.; Mazen, G. (2014) PWM Control of a DC motor used to drive a conveyor belt, 25th DAAAM International Symposium on Intelligent Manufacturing and Automation, DAAAM 2014, ISSN 1726-9679, Vienna, Austria

[5] Livinti, P. (2015) Speed control of a permanent magnet DC servomotor through Compactrio 9074, 26th DAAAM International Symposium on Intelligent Manufacturing and Automation, DAAAM 2015, ISSN 1726-9679, Vienna, Austria

[6] Mitin, F.; Krivushov, A. (2018) Application of Optimal Control Algorithm for DC Motor, Proceedings of the 29th DAAAM International Symposium, pp.0762-0766, B. Katalinic (Ed.), Published by DAAAM International, ISBN 978-3-902734-20-4, ISSN 1726-9679, Vienna, Austria DOI: 10.2507/29th.daaam.proceedings.110

[7] Dvořák, V.; Votrubec, R.; Šafka, J.; Kracík J. a P. Dančová. (2018) Experimental investigation of centrifugal fans for personal protection equipment - effect of used 3D printing technologies. EPJ Web of Conferences [online]. 2018, 180 [cit. 2019-10-13]. DOI: 10.1051/epjconf/201818002023. ISSN 2100-014X.

[8] Pongfai, J. \& Assawinchaichote, W. (2017). Optimal PID parametric auto-Adjustment for BLDC motor control systems based on artificial intelligence, 2017 International Electrical Engineering Congress, iEECON, 8-10 March 2017, Pattaya, Thailand, pp. 8075892, DOI: 10.1109/IEECON.2017.8075892 